\title{
Spouse's Work-to-family Conflict, Family Stressors, and Mental Health among Dual- earner Mothers and Fathers
}

\author{
Marisa Young, Scott Schieman, and Melissa A. Milkie
}

\begin{abstract}
Version Post-Print/Accepted Manuscript
Citation Young, Marisa, Scott Schieman, and Melissa Milkie. 2014. "Spouse's

(published version) Work-to-family Conflict, Family Stressors, and Mental Health among Dual-earner Mothers and Fathers." Society and Mental Health 4:1-20.
\end{abstract}

Publisher's Statement The final publication is available at SAGE Publications via https://dx.doi.org/10.1177/2156869313504931.

\section{How to cite TSpace items}

Always cite the published version, so the author(s) will receive recognition through services that track citation counts, e.g. Scopus. If you need to cite the page number of the TSpace version (original manuscript or accepted manuscript) because you cannot access the published version, then cite the TSpace version in addition to the published version using the permanent URI (handle) found on the record page. 


\section{Spouse's Work-to-Family Conflict, Family Stressors, and}

\section{Mental Health among Dual-Earner Mothers and Fathers}

\section{ABSTRACT}

We examine the association between perceptions of spouse's work-to-family conflict,

family stressors, and mental health outcomes using eross sectionat-data from a sample of 1,348 dual-earning parents from a 2011 nationally representative survey of Canadian workers. Based on crossover stress theory and the Stress Process Model, we hypothesize that perceptions of spouse's work-to-family conflict are associated with family stressors, which in turn mediate the association between perceptions of spouse's work-to-family conflict and individuals' mental health. Using ordinary least square regression techniques, we find that perceptions of spouse's work-to-family conflict are associated with mental health outcomes, as well as secondary family stressors.

Furthermore, the family stressors resulting from perceptions of spouse's work-to-family conflict facilitate family-to-work conflict among respondents, which further explains the association between perceptions of spouse's work-to-family conflict and mental health outcomes. We discuss the implications of these findings for theories of crossover stress and the Stress Process Model. 


\section{Spouse's Work-to-Family Conflict, Family Stressors, and}

\section{Mental Health among Dual-Earner Mothers and Fathers}

North Americans are increasingly reporting difficulties balancing paid work expectations and unpaid family obligations, which contributes to work-to-family conflict-a common problem affecting mental health in the $21^{\text {st }}$ century (Duxbury, Lyons, and Higgins 2008; Nomaguchi 2009). Within this context, researchers have sought to expand the scope of analyses beyond the individual's own consequences of work-to-family conflict to focus on the crossover stress it places on other family members (Bakker, Westman, and Hetty van Emmerik 2009; Westman 2001).

Dual-earning couples with children may be especially vulnerable to the crossover stress associated with work-to-family conflict. Roughly 70 percent of couples in the U.S. and 75 percent of couples in Canada are classified as "dual-earning"-a circumstance in which each spouse works an average of 30 to 40 hours per week, while trying to meet family obligations (Marshall 2009; ADD REF for U.S.). Among these couples, approximately 60 percent report at least moderate levels of work-to-family conflict, and this pattern is increasing particularly among men in both the U.S. and Canada (see Aumann, Galinsky, and Matos 2011; Bianchi, Robinson, and Milkie 2006;

Nomaguchi 2009, for U.S. figures; see Duxbury et al. 2008; Johnson, Lero, and Rooney 2001; Marshall 2009, for Canadian figures). These trends underscore the need for more research on the crossover stress of work-to-family conflict for both spouses.

Furthermore, the ways in which crossover stress impacts spouses' mental health remain unclear, despite research to date. Some scholars hypothesize that an individual's exposure to workrelated stressors elicits support and empathy from the other spouse who, in turn, becomes emotionally burdened by the person's stress (Westman 2001; Wethington 2000). Other research suggests that spouses' conflicting job demands foster work-to-family conflict that results in family-related problems like spousal disputes and problems with children, which may compromise 
the well-being of the other spouse (Bakker, Demerouti, and Dollard 2008; Matthews et al. 2006; Stevens, Kiger, and Riley 2006). It is also unclear whether these processes operate differently for men and women. Research from the 1980's finds that the effects of crossover stress are stronger for wives compared to husbands (Jackson and Maslach 1982; Long and Voges 1987). Yet, more recent studies report contrary or null findings (Hammer, Allen, and Grigsby 1997; Westman and Etzion 2005). These competing results may reflect changing gender roles (Doucet 2006).

We elaborate and clarify these arguments by examining one spouse's perception of the other SPWFC and the ways that these perceptions influence family stressors, family-to-work conflict, and mental health outcomes. ${ }^{1}$ We recognize that actual reports from spouses about their own work-to-family conflict might be the preferred measure instead of the respondent's perceptions (Geist 2010). Yet, we argue that the respondent's perceptions of their spouse's work-to-family conflict are of critical importance for the assessment of the respondent's reported family stressors Formatted: Font: Not Italic Formatted: Font: Not Italic and mental health. Regardless of a spouse's objective conflicts between work and family expectations, it is the perception of these actions that shape experiences of family processes and mental health outcomes (see Stevens et al. 2006; Wheaton 1997, for similar arguments).

Therefore, using the respondent's reports of their spouse's work-to-family conflict, we seek to answer the following research questions: (1) Are perceptions of spouses' work-to-family conflict associated with respondents' reports of family stressors (i.e., spousal disputes, problems with children, marital dissatisfaction) and family-to-work conflict? (2) Are perceptions of spouses' work-to-family conflict associated with respondents' distress and anger? 3) Do family stressors and family-to-work conflict mediate any observed association between perceptions of spouses' work-to-family conflict and respondents' levels of distress and anger? And, 4) Do any of these associations differ for mothers and fathers?

For the sake of clarity and consistency, we use the following acronyms from this point: 
- $\mathrm{SPWFC}=$ respondent's perception of their spouse's work-to-family conflict.

- $\mathrm{RWFC}=$ respondent's own experiences of work-to-family conflict.

- $\mathrm{RFWC}=$ respondent's own experiences of family-to-work conflict.

-WFC $=$ work-to-family conflict.

\section{THEORETICAL FRAMEWORK}

\section{Crossover Stress: Work-to-Family Conflict and its Consequences}

We conceptualize SPWFC as a form of crossover stress between closely related individuals. Crossover stress describes the processes where stressful experiences of one individual can influence the social and psychological experiences of a significant other (Bolger et al. 1989; Westman 2001; Wethington 2000). Crossover stress is a type of stress contagion, which involves "a cascade of demands and consequent emotional arousal from one area of life into another, between closely related individuals" (Thoits 1995; Wethington 2000:229).

Research on the nature and consequences of crossover stress is rooted in role theory (Kahn et al. 1964), because it considers not only the experiences of the individual in a given role, but also other actors surrounding that individual. Role theory underscores the fluidity of boundaries between roles - a notion central to the recent conceptualization of border theory, where the experiences of work and home are seen as intertwined, each affecting the other and creating the potential for conflict (Clark 2000). Crossover theory applies these ideas to assess the extent to which an individual is affected by closely-related others across various roles, such as work and family. Previous research finds ample evidence to support these theories in studies on spouse's occupation demands, burnout, and exhaustion finds ample evidence to support these theories 
(Bakker et al. 2008; Westman and Etzion 1995; see Westman 2001, for a review). Furthermore, studies on SPWFC find evidence ofdocument crossover stress for work, family, and health outcomes (Hammer et al. 2005; Stevens et al. 2006).

We situate our research in this literature and integrate inter-individual level processes as possible influences on dual-earners' stress experiences and mental health outcomes (Bakker and Demerouti 2009; Westman 2001). From this perspective, we first hypothesize that SPWFC reflects crossover stress that may have mental health consequences for the respondent.

Hypothesis 1: SPWFC will be positively associated with respondent's own levels of psychological mental health problemsdistress and anger.

\section{Crossover Stress and Mental Health}

Although the association between crossover stress and health is well documented, explanations for the linking mechanisms involved in these processes are less clear. One argument purports that the negative health effects of crossover stress may occur when one spouse feels a painful empathy in response to another's stressful experiences (Bolger et al. 1989; Bakker et al. 2009; Westman 2001; Wethington 2000). According to this perspective, stressors result in "direct empathetic crossover," where experiences of one individual produce an empathetic reaction in significant others, leading them to suffer additional stress or strain (Westman 2001:729). Thus, individuals may encounter psychological eonsequences-distress as a result of SPWFC because of the empathy they feel towards a loved one. Previous scholars have referred to this process as the cost of caring (Kessler and McLeod 1984; Wethington 2000). ${ }^{2}$

This so-called "empathy explanation" has largely dominated research on crossover stress to date (Bakker and Demerouti 2009; Westman 2001). Our study does not seek to directly test this 
theory. Instead, we draw attention to the potential mechanisms that may account for part of the association between SPWFC and individuals' mental health. We argue that SPWFC may disrupt the family sphere by inhibiting individuals' efforts to meet domestic obligations or invest time with other family members (Bolger et al. 1989; Hochschild 1989; Milkie 2010). These conditions may contribute to spousal disputes, problems among children, and marital dissatisfaction—-factors that, in turn, may mediate the association between SPWFC and mental health (see Bakker et al. 2008; Matthews et al. 2006, for similar arguments). By evaluating these potential mediating mechanisms, we move beyond the conventional empathy-focused explanations of crossover stress not sure...not a big deal. to incorporate a broader assessment of the secondary family stressors that SPWFC may instigate.

\section{Applying the Stress Process Model to Explain the Impact of Crossover Stress}

We draw upon the Leonard Pearlin's-Stress Process Model to clarify our points (Pearlin 1999). Specifically, we use concepts of primary stressors, secondary stressors, and stress proliferation to develop a conceptual framework for the mediating processes that may account forin the association between SPWFC and mental health. According to the Stress Process Model, the association between primary and secondary stressors is referred to as "stress proliferation," where one stressor creates additional stressors or exacerbates their effects. Integrating these concepts in our analyses, we hypothesize that SPWFC is related to family stressors, and that part association between SPWFC and respondents' mental healthdistress or anger might therefore be these secondary family stressors__, including spousal disputes, problems with children, and dissatisfaction (Matthews et al. 2006; Stevens et al. 2006; Westman and Vinokur 1998).

Although most previous research has neglected to emphasize the role of secondary family stressors for crossover stress and mental health, some limited evidence supports these ideas (Hammer et al. 2005; Matthews et al. 2006; Stevens et al. 2006). For example, Westman's (2001) 
review of crossover stress highlights that one spouse's role conflict may lead them to socially undermine the other spouse through displayed expressions of negative affect and increased reticence to support the other spouse's future endeavours. These actions can fuel spousal conflicts and decrease marital satisfaction, subsequently compromising both spouses' mental health (Westman and Vinokur 1998). These results parallel those in a study by Matthews et al. (2006), who examine respondent's perception of their spouses' work-to-family conflict. The authors find that SPWFC is associated with more relationship tensions that result in greater health

eonsequencessymptoms of distress, such as trouble sleeping, nervousness, stomach problems.

Based on these ideas and evidence, we hypothesize that SPWFC may be the catalyst for stress proliferation that crosses over and permeates family experiences, generating additional strains and elevating levels of distress/anger.

Hypothesis 2a: SPWFC will be positively associated with additional family stressors.

Hypothesis 2b: Family stressors should mediate the positive association between SPWFC and respondent's mental health consequencesdistress and anger. That is, SPWFC is associated with more psychological probtemsdistress and anger because it tends to increase exposure to family stressors.

SPWFC, Family Stressors and Respondent's Family-to-Work Conflict (RFWC)

Additional family stressors may result in elevated family-to-work conflict among respondents (RFWC), which could account for the remaining association between SPWFC and individual's mental health. In general, RFWC is defined as a form of inter-role conflict in which the pressures from the family domain are incompatible with the work domain. RFWC may arise when individuals experience an imbalance or incompatibility of resources and demands across 
family and work domains. Chronic family-to-work conflict can lead to fatigue, anxiety, distress, and anger. Most literature highlights antecedents of RFWC as arising from the family domain, such as stressors like spousal disputes, childcare obligations, and marital dissatisfaction (Byron 2005; Bellevia and Frone 2005).

In line with these ideas, we argue that SPWFC places additional pressure on the other spouse because it facilitates exposure to family stressors and RFWC secondarily. Moreover, based on more traditional approaches to crossover stress, it is possible that SPWFC activates a degree of empathy from the respondent, which might elevate emotional strain (Bolger et al. 1989;

Wethington 2000). While we do not test this argument directly, SPWFC may remain associated with RFWC net of secondary family stressors because of related feelings of empathy associated with the cost of caring. These pressures and emotions spill over into the work sphere and affect individuals' ability to meet paid work expectations. The resulting experience of RFWC may compromise dual earners' mental health.

Hypothesis 3a: SPWFC and family stressors will be positively associated with RFWC.

Hypothesis 3b: RFWC should partially mediate the positive associations between both SPWFC and family stressors. That is, SPWFC is associated with RFWC because it tends to increase exposure to family stressors.

Hypothesis 3c: RFWC will partially mediate the positive associations between family stressors, and respondent's mental health consequences. That is, family stressors are associated with more psychological problems because they tend to increase exposure to RFWC.

\section{Are Mothers and Fathers Different?}

We hypothesize that the focal associations outlined above may differ for mothers and fathers because of persistent gendered expectations in work and family spheres, as well as 
women's more generous consideration of others' problems (Glavin, Schieman, and Reid 2011; Hochschild 1989; Milkie et al. 2010; Rosenfield and Smith 2010). Our ideas here originate from theories on gender differences in self-salience and mental health (Kessler and McLeod 1984; Rosenfield and Smith 2010). Women tend to be more sensitive to others' based on gender socialization, and may be more aware of — and therefore more affected by — their husbands' workto-family conflict. As Rosenfield and Smith explain: “... self-salience involves who we put first, ourselves or other people" (p. 263). Women are socialized to put others first and hence become more concerned about, and more aware of others' experiences and behaviours. Alternatively, men tend to be socialized to be more concerned with the self, placing less weight on others' feelings, experiences, and situations (Rosenfield and Smith 2010). A gender perspective emphasizes the importance of cultural expectations for performance and power in everyday social relations (Ridgeway 2011). For wives, gender performance includes the display of stereotypical qualities attached to their gender, with empathy and deference still a key part of their role as wife (Butler 1990; West and Zimmerman 1987). Mothers' greater likelihood of being attuned to their spouse may be based is relative power, with everyday situations in the home, like asking about a partner's day being "read" with gender as a primary force shaping their relationship (Ridgeway 2011).

Women know their behavior to be socially evaluated based in their adhering to stereotypes and powerful expectations about being a "good wife".

Together, these perspectives suggest that women may be more reactive to SPWFC, resulting in more family stressors, RFWC, and mental health problems for women, compared to men. Previous research from the 1980's supports these ideas (Jackson and Maslach 1982; Long and Voges 1987). While limited, some recent research also highlights gender differences. For example, Demerouti, Bakker, and Schaufeli (2005) find that women reported more exhaustion, whereas men report more life dissatisfaction as a result of SPWFC. Based on this evidence, we 
hypothesize that the positive associations between SPWFC, family stressors, and mental health will be stronger for women compared to men.

Hypothesis 4: Compared to men, women should experience more family stressors, RFWC, and mental health problems as a result of SPWFC.

Despite the plausibility of this hypothesis, research on gender differences in crossover stress from the 2000's is rather sparse, and cannot shed much light on the topic. However, some studies using data from the 1990's suggest that the gender differences in the effect of crossover stress may be weaker than traditional theories might predict (Hammer et al. 1997; Westman et al. 2005). For example, Hammer and colleagues (1997) find that husbands' work salience and job schedule have no effect on their wives' WFC, whereas women's work salience — in terms of career priority —is actually negatively associated with their husband's WFC. The authors did not examine links to mental health, however. Research by Westman and Etzion (2005) report no gender differences in the effect of one spouse's reports of WFC on the other spouse, but this study was based on a highly specialized sample. Nevertheless, these contrary or null findings may reflect growing equality in gender behaviours in work and family spheres (Aumann et al. 2011; Doucet 2006).

\section{A Caveat to Consider: The Combined Effects of Spouses' Work-to-Family Conflict}

At this juncture, it is essential to take into account RWFC. In dual-earning families, both spouses are likely to report relatively high levels of work-to-family conflict, which may confound the effects of either spouse's work-to-family conflict on family stressors, RFWC, and mental health (Aumann et al. 2011). In particular, RWFC may bias reports of SPWFC. Because spouses do not always have sufficient information about the other, each individual may draw from his or her own experience to produce an estimate of the other's experience. Kenny and Acitelli (2001) refer to this process as assumed-similarity bias where one spouse may simply assume that the 
other's situation is similar to his or her own. Applied to our analyses, it may be that SPWFC reflects his or her own exposure to RWFC, at least to some degree. For these reasons, we test the effects of SPWFC and RWFC simultaneously to neutralize potential spurious associations and any assumed-similarity biases in respondents' reports. ${ }^{3}$

\section{Summary of Hypotheses}

Overall, our study attempts to disentangle the complex association between SPWFC and mental health (Hypothesis 1). We argue that SPWFC facilitates secondary family stressors, including spousal disputes, problems with children, and marital dissatisfaction (Hypotheses 2a, 2b), which then increase exposure to RFWC. Together, secondary family stressors and their resulting RFWC account for the association between SPWFC and the respondent's mental health (Hypotheses 3a, 3b, 3c). However, we hypothesize that our focal associations may differ for men and women (Hypotheses 4). In all analyses, we assess the impact of SPWFC and RWFC simultaneously. Figure 1 illustrates our hypotheses.

\section{[INSERT FIGURE 1 ABOUT HERE]}

\section{METHODS}

Sample To test the hypotheses outlined above, we analyze data from the 2011 Canadian Work Stress and Health study (CAN-WSH), a nationally representative sample of the Canadian labour force. Interviews were conducted by telephone between January and August 2011. To be eligible to participate in the study, individuals had to be: (1) residing in Canada, (2) 18 years of age or older, (3) currently working at a paid job or operating an income-producing business, (4) employed in the civilian labour force, and (5) live in a non-institutional residence. In households with more than one eligible person, we used the "next birthday" method to randomly select a study participant. Calls were made to a regionally stratified unclustered random probability sample generated by random-digit-dial methods. Interviews were conducted in English or French and 
averaged approximately 30-35 minutes. Study participants received a $\$ 20$ gift card for completing the interview. The final full sample included 6,004 participants, and was weighted by gender, age, marital status, and education according to distributions in the 2006 Canadian Census. The response rate was approximately 40 percent. We restrict analyses to respondents working fulltime based on Canadian standards (30 hours or more per week; see Statistics Canada, 2009) with a full-time working spouse, and at least one child in the household. Of the 6,004 , only 1,496 respondents met our criteria. The additional 148 were missing across focal measures, including SPWFC, education, age, and children's problems. However, these missing patterns appeared to be random and likely have limited influence on our overall analyses. Our final sample for the study yields 820 mothers and 528 fathers. Of these respondents 1,066 reported they were married and 282 were cohabiting.

\section{Focal Measures}

Psychological distress. We use seven items of generalized psychological distress originally from the K10 index developed by Kessler and colleagues (2002) and used in recently published research (Glavin et al. 2011; Young and Schieman 2012). These items ask about the frequency of the following symptoms in the past month: "anxious or tense," "nervous," "worry a lot about little things," "had trouble keeping your mind on what you were doing," "restless or fidgety," "sad or depressed," and "hopeless." Response choices are "all of the time" (1), "most of the time" (2), "some of the time" (3), "a little of the time" (4), and "none of the time" (5). We reverse-coded these responses and averaged the items to create the index; higher scores indicate greater levels of psychological distress $(\alpha=.83)$.

Anger. We use three items to assess study participants' experience of anger in the past month: "feel annoyed or frustrated," "angry," and "yell at someone or something." These items have been published in prior work that examines the social correlates and consequences of anger (Schieman 2010). Responses are coded as follows: "none of the time" (1), "a little of the time" (2), 
"some of the time" (3), "most of the time" (4), and "all of the time" (5). We averaged the items so that higher scores indicate more anger $(\alpha=.70)$.

Perceptions of spouse's work-to-family conflict (SPWFC). We assess SPWFC with an item that asks: "In the last three months, how often did your spouse's/partner's job interfere with home or family life." Response choices include "never" (1), "rarely” (2), "sometimes” (3), “often” (4), and "very often" (5), (adapted from the National Study of the Changing Workforce; see Families and Work Institute 2008). While single item measures of perceptions are not ideal, they have been used in previous research on crossover stress (Matthews et al. 2006; Stevens et al. 2006). ${ }^{4}$

Respondent's work-to-family conflict $(R W F C)$. We use four items to measure RWFC that are standard items used in recent research (Glavin et al. 2011), and are adapted from the National Study of the Changing Workforce (Family and Work Institute 2008). The items ask study participants how often in the last three months they have experienced the following: "not had enough time for the important people in your life because of your job," "not have the energy to do things with the important people in your life because of your job," "work kept you from doing as good a job at home as you could," and "job kept you from concentrating on important things in your family or personal life.” Response choices are "very often” (1), “often” (2), “sometimes” (3), "rarely" (4), and "never" (5). We reverse-coded and averaged items so that higher scores indicate more RWFC $(\alpha=.90)$.

Spousal disputes. We use one item to assess spousal disputes. Respondents were asked how often in the last three months they argued with their spouse about housework, finances, or their relationship. Responses include "never" (1), "rarely" (2), "sometimes" (3), “often” (4), and "very often" (5). Higher scores reflect more frequent disputes.

Children's problems. We use an index of three items to assess problems in the past three months. Respondents were asked how often any of their children had a) problems at school, b) 
problems with friends or peers, or c) health problems. Response choices are coded as follows: “never" (1), "rarely" (2), "sometimes" (3), "often" (4), and "very often" (5). We averaged the items to create the child problems index. Higher scores indicate more problems $(\alpha=.67)$. Only items applicable to the age of the child(ren) were included in the index. For example, if a respondent has only one child who is still an infant, the only applicable item relates to the child's health. We provide a breakdown of applicable responses by age of child in Appendix B.

Marital dissatisfaction was measured by three items where respondents were asked the extent to which they agree with the following statements: "I feel very close to my spouse/partner," "my spouse/partner takes the time to talk over my problems with me;" and "I know that my spouse/partner will always be there for me.” Response choices were "strongly disagree" (1), "somewhat disagree" (2), "somewhat agree" (3), and "strongly agree" (4).We reverse-coded and averaged the items so that higher scores reflect greater marital dissatisfaction $(\alpha=.77)$.

Respondent's family-to-work conflict $(R F W C)$. We use four items to measure RFWC. These standard items have been used in several national surveys, including the National Study of the Changing Workforce (Families and Work Institute 2008; also see Young and Schieman 2012). The items ask study participants how often in the last three months: "family or personal life kept you from doing as good a job at work as you could," "family or personal life keep you from concentrating on your job," "family or personal life drain you of the energy you needed to do your job," and "how often did you not have enough time for your job because of your family or personal life." Response choices are "very often" (1), "often” (2), "sometimes” (3), "rarely” (4), and "never" (5). We reverse-coded and averaged items such that higher scores indicate more $\operatorname{RFWC}(\alpha=.86)$.

\section{Control Measures}

Our analyses control for a variety of social, work- and family-related conditions. 
- Gender was coded 1 for women and 0 for men.

- Respondent's age is coded in years.

- Racelethnicity. We compare respondents who are white to all other ethnic categories. ${ }^{5}$

- Education is coded as a series of dummy variables "high school or GED" , "some college", “associate degree", "four-year college degree", and "graduate or professional degree", compared to "less than high school" (reference category).

- Personal income. We asked respondents about personal earnings in the year 2010 from all sources, before taxes. We divide this figure by 10,000 to clarify interpretations of effects. ${ }^{6}$

- Respondent's and spouse's work hours are measured as continuous variables.

- Respondent's previous mental health is measured with an item that asks about having ever received a diagnosis for a mental health condition. This item is a single, retrospective measure, and therefore limited. However, in cross-sectional data it is helpful to use reports of mental health problems in an attempt to correctly model causal associations.

- Spouse's general health. Participants were asked whether the health of their spouse was "poor" (1), "fair" (2), "very good" (3), "good" (4), or "excellent" (5) at the time of the survey.

- Number and age of children were measured using a series of continuous count variables for the number of children the respondent had living at home between the ages of 0-5 years, 6-11 years; and 12-18 years of age.

- Division of household labor includes measures of household chores and childcare, respondents were asked about the distribution of eight household tasks between themselves and their spouse (Sweet, Bumpass, and Call 1988). These tasks included a) preparing meals, b) laundry, c) cleaning house, d) shopping for groceries, e) dishes, f) getting children ready for school, $g$ ) helping children with homework, and h) organizing family activities. Response choices included 
(1) "you always do it"; (2) "you usually do it"; (3) "both you and your spouse do it"; (4) "your spouse usually does it"; or (5) "your spouse always does it." Higher scores indicate that spouses perform more domestic tasks $(\alpha=.87)$.

Plan of Analysis

Before testing our focal hypotheses, we examine gender differences across all variables included in our analyses (Table 1). We use t-tests for differences in means for continuous variables, and chi-square tests for our binary measures. Next, we test our focal hypotheses using ordinary least square regression techniques in Stata12. Our analytical approach resembles previous research that models complex processes between work, family, and health outcomes (Schieman and Young 2010; Young and Schieman 2012). We outline our specific approach below.

In Table 2, we first examine the impact of SPWFC on family stressors (Hypothesis 2) and RFWC (note that we estimate the impact of SPWFC on RFWC with and without family stressors in the equation; models 1 and 2, respectively).

In Tables 3 and 4 we estimate our mental health outcomes: Psychological distress and anger. In each table, model 1 tests the direct effect of SPWFC on mental health (Hypothesis 1). Model 2 considers the association between SPWFC and mental health, net of RWFC. Model 3 tests the mediating effects of family stressors simultaneously (Hypothesis 2b). Model 4 tests whether RFWC mediates the remaining association between SPWFC and mental health after accounting for family stressors (Hypothesis 3c). We use a formal Sobel test to determine significant mediating associations:

$$
z=\frac{a b}{\sqrt{b^{2} s a^{2}+a^{2} s b^{2}}}
$$

Where $a$ and $s_{a}$ represent the coefficient and standard error for the independent variable (e.g., SPWFC) on the mediating variable (e.g., spousal disputes), respectively. $b$ and $s_{b}$ represent the 


$$
z=\frac{a b}{\sqrt{b^{2} S a^{2}+a^{2} s b^{2}}}
$$

coefficient and standard error for the association between the independent variable (e.g., spousal disputes) and the outcome variable (e.g., distress), respectively. This test determines whether the association between the independent variable and the outcome variable is significantly different from zero. We use a standard probability $(\mathrm{p}<.05)$ to assess statistical significance (MacKinnon and Dwyer 1993).

To test gender differences across our focal associations (Hypothesis 4), we created and tested an interaction term between gender and SPWFC (i.e., gender $\mathrm{x}$ spwfc) on family stressors, RFWC, and our mental health outcomes (Hypothesis 4$){ }^{7}$

\section{RESULTS}

Table 1 reports descriptive statistics for all focal variables, highlighting differences between mothers and fathers. Mothers report higher levels of distress and anger compared to fathers. Mothers also perceive their spouses to have higher levels of SPWFC. Mothers report more spousal disputes, but similar levels of children's problems. Mothers tend to be more dissatisfied in their marriages and report more RFWC compared to fathers. In terms of general socioeconomic and demographic characteristics, the mothers and fathers in our sample are 40 years old on average, mostly white $(86 \%)$, and a high proportion have either a college or post graduate degree (42\%; $17 \%$, respectively). The average personal income is $\$ 60,000$, and most respondents report working an average of 39 hours per week, with spouses who work 41 hours per week. Only 15\% report previous mental health problems and most respondents perceive their spouse to be in "good" health (3.73). All other descriptive statistics and gender differences are reported in Table 1. Bivariate correlations for all study variables are presented in Appendix C.

\section{[INSERT TABLE 1 ABOUT HERE]}

SPWFC, Family Stressors, and RFWC 
Table 2 shows that SPWFC is associated positively with spousal disputes, problems with children, marital dissatisfaction, and RFWC, which provides partial support for Hypotheses 2a. Moreover, these patterns are statistically significant even after accounting for RWFC and other socio-demographic variations, suggesting that assumed-similarity bias does not influence our results. Model 2 estimating family-to-work conflict in Table 2 also shows that family stressors are positively associated with RFWC, which provides support for hypothesis 3a. Sobel z-tests of mediation suggest that these family stressors partially mediate the association between SPWFC and RFWC, with the exception of marital dissatisfaction $\left(\mathrm{z}_{\text {spousaldisputes }}=3.56, \mathrm{p}<.001\right.$; $\left.\mathrm{z}_{\text {childprob }}=3.09, \mathrm{p}<.05\right)$. These results provide partial support for Hypothesis $3 \mathrm{~b}$. However, the positive association between SPWFC and RFWC remains even when accounting for our three focal family stressors. In congruence with traditional theories of crossover stress and empathyfocused explanations, the remaining unexplained variance could reflect a certain level of empathy encompassed in SPWFC that, in turn, elevates RFWC.

\section{[INSERT TABLE 2 ABOUT HERE]}

SPWFC, Family Stressors, RFWC, and Psychological Distress

We report the results for distress in Table 3. In model 1, we find a significant positive association between SPWFC and distress, net of control variables (support for Hypothesis 1). In model 2, we observe that the significance of the effect of SPWFC remains stable net of RWFC;

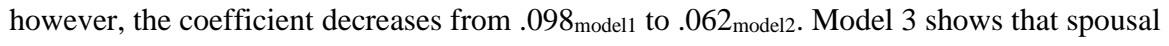
disputes, problems with children, and marital dissatisfaction are positively associated with distress (support for Hypothesis 2a). Moreover, these family stressors partially mediate the association between SPWFC and distress, with the exception of marital dissatisfaction (Sobel tests:

$\left.\mathrm{Z}_{\text {spousaldisputes }}=3.48, \mathrm{p}<.001 ; \mathrm{z}_{\text {childprob }}=2.19, \mathrm{p}<.05\right)$. Together, these results provide partial support for Hypothesis $2 b$. 
Model 4 shows a positive association between RFWC and distress, net of family stressors. More importantly, RFWC accounts for the remaining association between SPWFC and distress. A Sobel test confirms this mediating effect $\left(\mathrm{z}_{\mathrm{rfwc}}=3.57, \mathrm{p}<.001\right)$. In combination with the previous results from Table 2, these findings support our hypotheses: SPWFC is positively associated with family stressors, which spill over into the work sphere, resulting in RFWC and subsequent distress.

SPWFC, Family Stressors, RFWC, and Anger

We report the results for anger in Table 4. In model 1, we find a significant positive association between SPWFC and anger, net of control variables (support for Hypothesis 1). In model 2, we observe that the effect of SPWFC remains stable net of RWFC. Model 3 shows that spousal disputes and problems with children are positively associated with anger (support for Hypothesis 2a). Results also suggest that these stressors partially mediate the association between SPWFC and anger (Sobel tests: $\mathrm{Z}_{\text {spousaldisputes }}=4.00, \mathrm{p}<.001 ; \mathrm{Z}_{\text {childprob }}=2.62, \mathrm{p}<.01$ ). Together, these findings provide partial support for Hypothesis $2 b$.

Model 4 shows a positive association between RFWC and distress, net of family stressors. RFWC partially mediates the remaining association between SPWFC and anger $\left(\mathrm{z}_{\mathrm{rfwc}}=2.20, \mathrm{p}<\right.$ .05). However, unexplained variation in respondents' anger levels remains net of family stressors and RFWC $\left(b_{\bmod 3}=.05, p<.01 ; b_{\bmod 4=.042} \mathrm{p}<.05\right)$. We are not suggesting, however, that these factors do not influence anger. Instead, we highlight that additional unobserved measures may account for the remaining association between SPWFC and anger.

In tests of our gender hypothesis, we did not find significant differences for mothers and fathers in the effect of SPWFC on a) family stressors, b) RFWC, or c) mental health outcomes (no support for Hypothesis 4). We therefore do not present these analyses in the tables, but will provide these results to readers upon request. 


\section{[INSERT TABLES 3 and 4 ABOUT HERE]}

\section{DISCUSSION}

Our study examined the association between SPWFC, family stressors, RFWC, and mental health outcomes, net of RWFC. We also examined whether family stressors and RFWC mediate any observed associations, and whether our proposed hypotheses differed for mothers and fathers. Drawing on theories of crossover stress and the Stress Process Model, we use data from a sample of dual-earning parents from a nationally representative survey of Canadians to examine four specific research questions. Our findings reveal several noteworthy patterns. In general, SPWFC is positively associated with (1) family stressors, including spousal disputes, problems with children, and marital dissatisfaction, (2) RFWC, and (3) mental health problems, including distress and anger. We also find that family stressors — specifically spousal disputes and children's problemsand RFWC fully account for the association between SPWFC and distress, and partially account for the association between SPWFC and anger. Contrary to our expectations, we do not find gender differences among our observed associations. Below, we discuss the implications of these results for crossover stress, the Stress Process Model, and the work-family interface.

\section{Crossover Stress and the Stress Process}

Several of our findings are consistent with theories of crossover stress, which argue that stressful experiences of one individual can determine the social and psychological experiences of a significant other (Bakker et al. 2009; Bolger et al. 1989; Westman 2001; Wethington 2000). SPWFC represents a form of crossover stress that affects the other spouse in multiple ways. However, as predicted in the Stress Process Model, the association between SPWFC and respondent's mental health may be a product of secondary family stressors, and the RFWC that often results from family stressors (Byron 2005; Pearlin 1999). SPWFC appears to be the catalyst for stress proliferation that pervades individuals' family-related experiences. Spousal disputes and 
problems with children provide the strongest evidence for the hypothesized association between SPWFC and respondents' mental health, compared to marital dissatisfaction, which does not mediate the associations between SPWFC and RFWC or mental health outcomes net of other conditions. This lack of a mediating influence might be due to (a) the fact that the link between SPWFC and marital dissatisfaction is weaker than its link to spousal disputes and problems with children; and (b) the fact that spousal disputes are predictive of marital dissatisfaction. Taken together, these factors undermine the overall mediating potential of marital dissatisfaction.

We further predicted that stressors that arise in the family sphere because of SPWFC may disrupt work expectations, resulting in RFWC. We find some support for these ideas: Family stressors partially mediate the association between SPWFC and RFWC. Furthermore, RFWC explains the remaining association between SPWFC and distress after accounting for family stressors. We do not find the same pattern of results for anger, however. Our findings here instead suggest that SPWFC is directly associated with anger. However, this association is only partially mediated by family stressors. While these differences among our outcomes of distress and anger are relatively minor, they do underscore the importance of considering multiple mental health outcomes (Aneshensel, Rutter, and Lachenbruch 1991).

What could explain these different patterns between distress and anger? Individuals may experience some direct level of frustration to their SPWFC. Alternatively, the distressing consequences of SPWFC may not be experienced as directly, and instead, manifest in reaction to secondary family stressors and RFWC.

\section{The Importance of Empathy-Focused Explanations}

The net unexplained association between SPWFC and anger may also reflect unmeasured family stressors, or the elicited empathy and emotional burden endured as a result of another's experienced stressor (Bolger et al. 1989; Wethington 2000). For these individuals, it may be that 
the cost of caring manifests as anger. Some individuals may be annoyed, irritated, and resentful of their spouse's WFC. Alternatively, it may be that the association between SPWFC and anger would be even greater were it not for a certain level of empathy one spouse feels towards the other. Given limitations of our data we cannot test these ideas, but encourage others to do so.

Processes associated with empathy may also be relevant for the association between SPWFC and RFWC. Based on conventional approaches to crossover stress, it is possible that SPWFC activates empathy from the respondent, which results in emotional strain. While we cannot test these claims directly, we find that SPWFC is associated with RFWC even after we account for secondary family stressors. We speculated that the elicited empathy associated with the cost of caring may spill over into the work sphere and affect individuals' ability to meet paid work expectations, elevating RFWC, and its associated mental health problems. Again, however, these ideas are speculative, and require more refined measures and analyses of family stressors.

\section{Comparing Mothers and Fathers}

We do not find gender differences in the association between SPWFC, family stressors, RFWC, and mental health outcomes, which is inconsistent with theoretical perspectives on gender differences in self-salience and gendered perspectives of work and family spheres (Hochschild 1989; Rosenfield and Smith 2010). The lack of gender differences does not, however, contradict research on crossover stress. As we noted in the introduction, recent studies report contrary or null findings (e.g., Hammer et al. 1997; Westman and Etzion 2005). Our observations may reflect the growing equality in gender behaviours across work and family spheres. It may be that men are as likely to detect and react to SPWFC as women - patterns that go against the grain of traditional theories of gender roles and salience. Indeed, some research finds that women are increasingly playing a more prominent role in the economic sustainability of the household, while men are participating more in domestic-related responsibilities compared to previous decades (Aumann et 
al. 2011; Doucet 2006). The descriptive statistics presented in Table 1 help support our conclusion that the lack of gender differences in our findings may reflect men's and women's changing roles in the public and private sphere. The full-time working mothers and fathers in our data report preforming similar levels of domestic tasks (relative to their spouses), number of children, and income levels, suggesting relatively equitable financial provision from both spouses in respondents' households. These changing gender roles in public and private spheres may account for our comparable findings for mothers and fathers in the association between SPWFC, family stressors, RFWC, and mental health outcomes.

\section{Current Contributions and Future Research}

Our study makes several contributions to the literature. First, we use a large, nationally representative survey of working Canadians, and limit our analyses to individuals whose crossover stress from spouses is arguably most potent, including those in dual-earner households with at least one child. By contrast, prior studies on crossover stress rely on small samples of individuals, often in specific occupations, which limit generalizability and analyses across subgroups (Bakker 2009; Matthews et al. 2006; Stevens et al. 2006).

Second, our findings contribute theoretically to research on crossover stress and mental health by considering the proliferation of secondary stressors that often arise immediately or insidiously as a result of SPWFC. Previous research on crossover stress often overlooks these potential processes. Such an oversight may result from a disconnection between theories of crossover stress and the Stress Process Model. Our study begins to bridge this gap by considering alternative processes though which individuals may be affected by their spouse's WFC, while also highlighting how these associations play out differently for mothers and fathers. We hope that our study encourages future researchers to use the Stress Process Model in combination with crossover theories to clarify how stressors affect closely related others. 
Despite these contributions, several limitations deserve mention. First, our data are cross sectional in nature and therefore cannot effectively disentangle the causal order of our focal associations. Based on prior theory and evidence, we have made the case that SPWFC precedes family stressors, RFWC, distress, and anger. However, it could be that family stressors influence work-to-family conflict, or that mental health experiences contribute to family problems. We have sought to address these issues by adjusting for a retrospective measure of respondent's mental health in our models, (although we acknowledge this measure is limited, and longitudinal data would be useful to establish these causal processes). Nevertheless, our study provides a snapshot of patterns that might guide future research to more accurately assess the processes that link SPWFC to different mental health outcomes.

Second, our measure of spousal disputes is single-item measure, with a moderately skewed distribution (skewness=.59). We recognize that a single item measure has its limits and might not fully capture the underlying construct. We have specific plans to conduct a series of in-depth qualitative interviews with a proportion of these study participants that directly inquire about family stressors, including spousal disputes. Findings from the current study present a preliminary portrait as a starting point for understanding this multifaceted construct.

Third, we do not have indicators of other family and work-related resources that may lessen RWFC for either spouse, including family-friendly workplace cultures or childcare arrangements (Bellavia and Frone 2005). Additional support from workplaces may reduce crossover stress between spouses, while lessening family stressors, RFWC, and mental health problems that may arise secondarily. We also lack measures on the duration of the respondents' marriage or cohabitation with their spouse, which may impact our focal associations. For example, family stressors may be more prevalent among new couples with young children. 
Fourth, our data pool together married and cohabiting individuals because of the small number of cohabiters in the sample. We recognize, however, that the results may vary across these subgroups. For example, married individuals may report greater relationship stability, fewer disputes and better mental health, compared to their unmarried counterparts. These differences would likely impact our associations between crossover stress, family stressors, RFWC, and mental health. We encourage future researchers to explore these possible variations.

Finally, we cannot test the strength of our argument against empathy-focused explanations of crossover stress because we lack measures of empathy. We have alluded to the drawbacks of this limitation, in terms of the association between SPWFC and RFWC, and SPWFC and anger. Nonetheless, our research does provide a starting point for other researchers to test competing associations, involving intervening mechanisms of family stressors, and RFWC, and the elicited empathy crossover stress precipitates.

\section{CONCLUSION}

Despite these limitations, our study presents a novel approach to examining the association between SPWFC, family stressors, and mental health outcomes, net of RWFC. We hypothesized that SPWFC facilitates secondary family stressors, which leads to RFWC. Together, these processes may mediate the association between SPWFC and individuals' mental health outcomes. Our results provide evidence for our hypothesized associations: SPWFC is associated with mental health outcomes (distress and anger), as well as secondary family stressors (spousal disputes, problems with children, and marital dissatisfaction). Furthermore, the family stressors that arise from SPWFC lead to RFWC among respondents. These processes fully account for the association between SPWFC and distress, and partially account for the association between SPWFC and anger. Contrary to our hypotheses, we do not find gender differences across our focal associations. 
Our study builds upon theories of crossover stress by disentangling the complex stress processes through which one spouse's experiences of RWFC may be personally damaging to the other spouse. 


\section{NOTES}

1. We define "spouse" as cohabiting and/or married partners.

2. Some scholars argue that empathy moderates crossover stress processes, while others consort that feelings of empathy actually explain this process (Bakker et al. 2009; see Westman 2001, for a review)

3. We also considered the possibility that RWFC may moderate the deleterious effects of SPWFC on family stressors, RFWC, and mental health. For example, there will likely be more spousal disputes and problems among children if neither spouse can attend to marital or parental matters because of conflicting work and family obligations. We tested these associations in a series of models by regressing each of our focal outcomes on the interaction term RWFC x SPWFC. However, we did not find any support that RWFC moderates the effects of SPWFC on family stressors, RFWC, and mental health.

4. We took several steps to validate our measures of perceived SPWFC. We compared the bivariate correlation for RWFC and SPWFC, which turned out to be quite low $(r=.15, \mathrm{p}<$ .05 , see Appendix C). Based on these results, we assumed that SPWFC is not strongly associated with RWFC. We attempted to further assess the validity of respondents' subjective reports by regressing SPWFC on more objective criteria related to spouses' work obligations, including respondents' reports of their spouse's work hours and occupation (results presented in Appendix A). Combined, these factors explain over 11\% of the variance in perceptions of spouse's WFC. Results also suggested that professional spouses (compared to spouses in administrative or production jobs), who work more hours, are perceived to have more WFC, which is consistent with previous theory (see Byron 2005; Bellevia and Frone 2005, for a review). 
5. Over 85 percent of our sample is white, which is why we use this group as the predominant measure in all analyses. Other race/ethnic categories included the following: Asian, 4.57\%; black, 2.35\%; First Nations, 1.85\%; some other race/ethnic group, $4.13 \%$.

6. For cases that had initially refused or did not know their personal income (9\%), we asked a follow-up question that provided broader ranges of income categories: $\$ 25,000$ or less, $\$ 25-\$ 50,000, \$ 50-\$ 75,000, \$ 75-\$ 100,000, \$ 100-\$ 125,000$, and more than $\$ 125,000$. Using these responses, we imputed the middle value of each category. For example, if respondents did not report their personal income in dollars, but said their income falls between $\$ 50,000$ and $\$ 75,000$, they were assigned a value of $\$ 62,500$. We include a missing flag measure in all analyses to account for the imputed missing values from the folding scale question, coded ' 1 ' for originally missing and ' 0 ' for not. If this measure is significant in any of the models, it suggests that the results for missing income cases are different compared to those not missing in the original data. This variable was not significant in any of our analyses, and therefore, missing cases on income are unlikely to influence our final results. Our measure of personal income also included approximately 20 outlier cases, where respondents reported incomes greater than $\$ 6,000,000$. We top coded these values to the $95^{\text {th }}$ percentile ( $\$ 200,000$; see Sarkisian 2007 , for similar approaches). This variable in normally distributed (skewness=.37). We divide personal income by 10,000 in all analyses to generate more interpretable coefficients.

7. Prior to creating these interaction terms, we centered variables to reduce multi-collinearity between lower-order and interaction terms (Aiken and West 1996). 


\section{REFERENCES}

Aiken, Leona and Stephen West. 1991. Multiple Regression: Testing and Interpreting Interactions. Thousand Oaks, CA: Sage.

Aneshensel, Carol S., Carolyn M. Rutter, and Peter A. Lachenbruch. 1991. "Social Structure, Stress, and Mental Health: Competing Conceptual and Analytic Models.” American Sociological Review 56:166-78.

Aumann, Kerstin, Ellen Galinsky, and Kenneth Matos. 2011. The New Male Mystique. Families and Work Institute. Retrieved November 12, 2011

(http://familiesandwork.org/site/research/reports/newmalemystique.pdf).

Bakker, Arnold B. and Evangelia Demerouti. 2009. "The Crossover of Work Engagement between Working Couples: A Closer Look at the Role of Empathy.” Journal of Managerial Psychology 24:220-36.

Bakker, Arnold B., Evangelia Demerouti, and Maureen Dollard. 2008. "How Job Demands Affect Partners' Experience of Exhaustion: Integrating Work-Family Conflict and Crossover Theory." Journal of Applied Psychology 93:901-11.

Bakker, Arnold B., Mina Westman, and Hetty van Emmerik. 2009. "Advances in Crossover Theory." Journal of Managerial Psychology 24:206-19.

Bellavia, Gina M. and Michael Frone. 2005. "Work-Family Conflict.” Pp. 113-48 in Handbook of Work Stress, edited by J. Barling, K. Kelloway, and M. R. Frone. Thousand Oaks, CA: Sage.

Bianchi, Suzanne M., James P. Robinson, and Melissa A. Milkie. 2006. Changing Rhythms of American Family Life. New York: Russell Sage.

Bolger, Niall, Anita DeLongis, Ronald C. Kessler, and Elaine Wethington. 1989. "The Contagion of Stress across Multiple Roles.” Journal of Marriage and Family 51:175-83. 
Butler, Judith. 1990. Gender Trouble: Feminism and the Subversion of Identity. New York: Routledge.

Byron, Kristin. 2005. “A Meta-Analytic Review of Work-Family Conflict and its Antecedents.” Journal of Vocational Behavior 62:169-98.

Clark, Sue C. 2000. "Work/Family Border Theory: A New Theory of Work/Family Balance." Human Relations 53:747-70.

Demerouti, Evangelia, Arnold B. Bakker, and Wilmar B. Schaufeli. 2005. "Spillover and Crossover of Exhaustion and Life Satisfaction among Dual Earning Parents.” Journal of Vocational Behavior 67: 266-89.

Doucet, Andrea. 2006. Do Men Mother? Fathering, Care, and Domestic Responsibility. Toronto, ON. University of Toronto Press Inc.

Duxbury, Linda, Shawn Lyons, and Christopher Higgins. 2008. “Too Much To Do, and Not Enough Time: An Examination of Role Overload.” Pp. 125-40 in Handbook of WorkFamily Integration: Research, Theory, and Best Practices, edited by K. Korabik, D. S. Lero, and D. L. Whitehead. London, UK: Academic Press/Elsevier.

Families and Work Institute. 2008. National Study of the Changing Workforce. New York: Alfred P. Sloan Foundation.

Geist, Claudia. 2010. “Men's and Women's Reports about Housework.” Pp. 217-40 in Dividing the Domestic: Men, Women, and Household Work in Cross-National Perspective, edited by J. Treas and S. Drobnič. Stanford, CA: Stanford University Press.

Glavin, Paul, Scott Schieman, and Sarah Reid. 2011. "Boundary-Spanning Work Demands and their Consequences for Guilt and Psychological Distress.” Journal of Health and Social Behavior 52:43-57. 
Hammer, Leslie, Elizabeth Allen, and Tenora D. Grigsby. 1997. "Work-Family Conflict in DualEarner Couples: Within Individual and Crossover Effects of Work and Family.” Journal of Vocational Behavior 50:185-203.

Hammer, Leslie, Jennifer Cullen, Margaret B. Neal, Robert R. Sinclair, and Margarita V. Shafiro. 2005. "The Longitudinal Effects of Work-Family Conflict and Positive Spillover on Depressive Symptoms among Dual-Earner Couples.” Journal of Occupational Health Psychology 10: 138-54.

Hochschild, Arlie R. 1989. The Second Shift. New York: Viking Penguin.

Jackson, Susan, E. and Christina Maslach. 1982. “After-Effects of Job-Related Stress: Families as Victims.” Journal of Occupational Behaviour 3: 63-77.

Johnson, Karen L., Donna S. Lero, and Jennifer Rooney. 2001. Work-Life Compendium 2001: 150 Canadian Statistics on Work, Family \& Well-Being. Guelph, ON: University of Guelph Centre for Families, Work \& Well-Being.

Kahn, Robert, Donald M. Wolfe, Robert P. Quinn, Diedrick Snoek, and Robert A. Rosenthal. 1964. Organizational Stress: Studies in Role Conflict and Ambiguity. New York: Wiley. Kenny, David A. and Linda K. Acitelli. 2001. "Accuracy and Bias in the Perception of the Partner in a Close Relationship.” Journal of Personality and Social Psychology 80: 439-48.

Kessler, Ronald C. and Jane D. McLeod. 1984. "Sex Differences in Vulnerability to Undesirable Life Events.” American Sociological Review 49:620-31.

Kessler, Ronald C., G. Andrews, L. J. Colpe, E. Hiripi, D. K. Mroczek, S. L. Normand, E. E. Walters, and A. M. Zaslavsky. 2002. "Short Screening Scales to Monitor Population Prevalences and Trends in Non-Specific Psychological Distress." Psychological Medicine 32: $959-76$. 
Long, Nigel, R. and Kevin E. Voges. 1987. "Can Wives Perceive the Source of their Husbands' Occupational Stress?” Journal of Occupational Psychology 60:235-42.

MacKinnon, David, P. and James H. Dwyer. 1993. "Estimating Mediated Effects in Prevention Studies.” Evaluation Review 17:144-58.

Marshall, Katherine. 2009. “The Family Work Week.” Perspectives on Labour and Income.Vol. 10, no. 4. April. Statistics Canada Catalogue no. 75-001-XIE.

Matthews, Russell A., Regan E. Del Priore, Linda, K. Acitelli, and Janet L. K.Barnes-Farrell. 2006. "Work-to-Relationship Conflict: Crossover Effects in Dual-Earner Couples." Journal of Occupational Health Psychology 11:228-40.

Milkie, Melissa A. 2010. “The Stress Process: Some Family-Level Considerations.” Pp. 93-108 in Advances in the Conceptualization of the Stress Process: Essays in Honor of Leonard I. Pearlin, edited by W. R. Avison, C. S. Aneshensel, S. Schieman, and B. Wheaton. New York: Springer.

Milkie, Melissa A., Sarah M. Kendig, Kei M. Nomaguchi, and Kathleen E. Denny. 2010. “Time with Children, Children's Well-Being and Work-Family Balance among Employed Parents.” Journal of Marriage of the Family 72:1329-43.

Nomaguchi, Kai M. 2009. “Change in Work-Family Conflict among Employed Parents between 1977 and 1997." Journal of Marriage and Family 71:15-32.

Pearlin, Leonard I. 1999. “The Stress Process Revisited: Reflections on Concepts and their Interrelationships.” Pp. 395-415 in The Handbook of the Sociology of Mental Health, edited by C. S. Aneshensel and J. C. Phelan. New York: Kluwer.

Ridgeway, Cecilia L. 2011. Framed by Gender: How Gender Inequality Persists in the Modern World. New York: Oxford University Press. 
Rosenfield, Sarah and Dena Smith. 2010. “Gender and Mental Health.” Pp. 256-67 in A Handbook for the Study of Mental Health: Social Contexts, Theories, and Systems, 2nd edition, edited by T. Scheid and T. Brown. New York: Cambridge University Press.

Sarkisian, Natalia. 2007. “Street Men, Family Men: Race and Men’s Extended Family Integration." Social Forces 86: 763-94.

Schieman, Scott and Marisa Young. 2010. "The Demands of Creative Work: Implications for the Stress in the Work-Family Interface.” Social Science Research 39: 246-59.

Schieman, Scott. 2010. "The Sociological Study of Anger: A Review of Social Patterns and Contexts.” Pp. 329-347 in A Handbook of Anger: Constituent and Concomitant Biological, Psychological, and Social Processes, edited by M. Potegal, G. Stemmler, and C. Spielberger. New York: Springer.

Statistics Canada. 2009. Labour Force and Participation Rates by Sex and Age Group. Retrieved November 12, 2011 (http://www40.statcan.gc.ca/101/cst01/labour05-eng.htm).

Stevens, Daphne P., Gary Kiger, and Pamela J. Riley. 2006. "His, Hers, or Ours? Work-to-Family Spillover, Crossover, and Family Cohesion.” The Social Science Journal 43:425-36.

Sweet, James, Larry Bumpass, and Vaughn Call. 1988. "The Design and Content of the National Survey of Families and Households NSFH Working Paper No. 1.” Madison, WI University of Wisconsin: Centre for Demography and Ecology.

Thoits, Peggy A. 1995. "Stress, Coping, and Social Support Processes: Where Are We? What Next?” Journal of Health and Social Behavior 35:53-79.

West, Candace and Don H. Zimmerman. 1987. "Doing Gender." Gender and Society 1:125-51. Westman, Mina and Dalia Etzion. 1995. "Crossover of Stress, Strain, and Resources from One Spouse to Another.” Journal of Organizational Behavior 16:169-81. 
Westman, Mina, Giora Keinan, IIan Toziner, Yael Benyamini. 2008. “The Crossover of Perceived Health between Spouses.” Journal of Occupational Health Psychology 13:168-80.

Westman, Mina. 2001. “Stress and Strain Crossover.” Human Relations 54:717-51.

Wethington, Elaine. 2000. “Contagion of Stress.” Advances in Group Processes 17:229-53.

Wheaton, Blair. 1997. "The Nature of Chronic Stress.” Pp. 43-73 in Coping with Chronic Stress, edited by B. H. Gottlieb. New York: Plenum Press.

Young, Marisa and Scott Schieman. 2012. "When Hard Times Take a Toll: The Distressing Consequences of Economic Hardship and Life Events Within the Family-Work Interface.” Journal of Health and Social Behavior 53:84-98. 
Table 1 Summary Statistics for all Study Variables

\begin{tabular}{|c|c|c|c|c|c|c|}
\hline \multirow[t]{3}{*}{ Focal Measures } & \multicolumn{2}{|c|}{ Mothers $(\mathrm{N}=820)$} & \multicolumn{2}{|c|}{ Fathers $(\mathrm{N}=528)$} & \multicolumn{2}{|c|}{$\begin{array}{c}\text { Total Sample } \\
(\mathrm{N}=1,348)\end{array}$} \\
\hline & $\%$ or & & $\%$ or & & $\%$ or & \\
\hline & Mean & SD & Mean & SD & Mean & SD \\
\hline Psychological distress & 2.21 & .68 & 2.05 & .64 & $2.14 * * *$ & .67 \\
\hline Anger & 2.46 & .69 & 2.36 & .69 & $2.42 * *$ & .69 \\
\hline SPWFC & 2.38 & 1.11 & 2.03 & 1.00 & $2.24 * * *$ & 1.08 \\
\hline RWFC & 2.64 & 1.03 & 2.68 & 1.00 & 2.66 & 1.02 \\
\hline Spousal disputes & 2.42 & 1.01 & 2.30 & .96 & $2.38 *$ & .99 \\
\hline Children's problems & 1.81 & .69 & 1.80 & .69 & 1.81 & .69 \\
\hline Marital dissatisfaction & 1.36 & .51 & 1.29 & .42 & $1.33 * *$ & .49 \\
\hline RFWC & 2.00 & .78 & 1.87 & .71 & $1.95 * * *$ & .78 \\
\hline Age & 39.63 & 7.23 & 41.62 & 7.66 & $40.41 * * *$ & 7.40 \\
\hline White & .86 & - & .86 & - & .86 & - \\
\hline Less than high school & .03 & - & .06 & - & .04 & - \\
\hline High school & .14 & - & .15 & - & .15 & - \\
\hline Associates degree & .11 & - & .11 & - & .11 & - \\
\hline Some college & .11 & - & .13 & - & .12 & - \\
\hline College & .46 & - & .37 & - & .42 & - \\
\hline Post graduate degree & .16 & - & .18 & - & .17 & - \\
\hline Personal income $^{a}$ & 5.00 & 4.09 & 7.35 & 3.63 & 6.00 & 4.00 \\
\hline Work hours & 35.36 & 12.35 & 44.74 & 11.76 & $39.04 * * *$ & 12.96 \\
\hline Spouse's work hours & 44.83 & 10.45 & 35.40 & 11.51 & $41.13 * * *$ & 11.81 \\
\hline Previous mental health & .19 & .39 & .09 & .29 & .15 & .36 \\
\hline Spouse's general health & 3.73 & .94 & 3.74 & .98 & 3.73 & .95 \\
\hline Children under 6 & .57 & .75 & .52 & .72 & .56 & .74 \\
\hline Children 6 to 11 & .63 & .78 & .59 & .77 & .61 & .78 \\
\hline Children 12 to 18 & .66 & .81 & .67 & .87 & .66 & .83 \\
\hline Domestic tasks & 3.77 & .55 & 2.70 & .53 & 3.35 & .75 \\
\hline
\end{tabular}

$* p<.05, * * p<.01, * * * p<.001$ two-tailed test.

Asterisks reflect significant gender differences.

Notes: SPWFC = Respondent's perceptions of their spouse's work-to-family conflict. RWFC=Respondent's work-to-family conflict. $\mathrm{RFWC}=$ Respondent's family-to-work conflict. ${ }^{a}$ Personal income was divided by 10,000 throughout all analyses. 
Table 2 Regressions of Family Stressors and Respondent's Family-to-Work Conflict on SPWFC $(N=1,348)$

\begin{tabular}{|c|c|c|c|c|c|c|c|c|c|c|}
\hline \multirow{3}{*}{ Variable } & \multirow{2}{*}{\multicolumn{2}{|c|}{ Spousal Disputes }} & \multirow{2}{*}{\multicolumn{2}{|c|}{$\begin{array}{l}\text { Children's } \\
\text { Problems }\end{array}$}} & \multirow{2}{*}{\multicolumn{2}{|c|}{$\begin{array}{c}\text { Marital } \\
\text { Dissatisfaction }\end{array}$}} & \multicolumn{4}{|c|}{ Family-to-Work Conflict } \\
\hline & & & & & & & \multicolumn{2}{|c|}{ Model 1} & \multicolumn{2}{|c|}{ Model 2} \\
\hline & $b$ & SE & $b$ & SE & $b$ & SE & $b$ & SE & $b$ & SE \\
\hline SPWFC & $.138^{* * *}$ & $*(.029)$ & $.068 * *$ & $*(.018)$ & $.029 *$ & $(.013)$ & $.141 * *$ & $(.020)$ & $.108 * *$ & $*(.020)$ \\
\hline RWFC & $.117 * * *$ & $*(.030)$ & $.082 * *$ & $*(.019)$ & $.062 * * *$ & $*(.013)$ & $.240 * *$ & (.023) & $.204 * *$ & $*(.022)$ \\
\hline \multicolumn{11}{|l|}{ Family Stressors } \\
\hline Spousal disputes & \multicolumn{2}{|c|}{ - } & \multicolumn{2}{|c|}{ - } & \multicolumn{2}{|c|}{ - } & \multicolumn{2}{|c|}{ - } & \multicolumn{2}{|c|}{$.120^{* * *}(.022)^{c}$} \\
\hline Children's problems & \multicolumn{2}{|c|}{ - } & \multicolumn{2}{|c|}{ - } & \multirow{2}{*}{\multicolumn{2}{|c|}{ - }} & \multicolumn{2}{|c|}{ - } & \multicolumn{2}{|c|}{$.182^{* * * *(.034)^{c}}$} \\
\hline Marital dissatisfaction & \multicolumn{2}{|c|}{ - } & \multicolumn{2}{|c|}{ - } & & - & \multicolumn{2}{|c|}{ - } & \multicolumn{2}{|c|}{$.089 * *(.046)$} \\
\hline \multicolumn{11}{|l|}{ Focal Controls } \\
\hline Gender (female) & -.041 & $(.079)$ & -.036 & $(.053)$ & $-.103 * *$ & $(.037)$ & .015 & $(.056)$ & .032 & $(.054)$ \\
\hline Age & $-.015^{* *}$ & $(.005)$ & -.001 & $(.003)$ & .003 & $(.002)$ & -.004 & $(.003)$ & -.002 & $(.003)$ \\
\hline White & $-.177 *$ & $(.078)$ & .014 & $(.052)$ & -.031 & $(.036)$ & -.057 & $(.053)$ & -.037 & $(.052)$ \\
\hline High school ${ }^{a}$ & .057 & $(.163)$ & -.015 & $(.101)$ & .082 & $(.069)$ & -.044 & $(.120)$ & -.052 & $(.111)$ \\
\hline Associates degree ${ }^{a}$ & .007 & $(.167)$ & -.021 & $(.104)$ & .075 & $(.072)$ & .050 & $(.124)$ & .048 & $(.113)$ \\
\hline Some college ${ }^{a}$ & -.051 & $(.165)$ & -.016 & $(.104)$ & .034 & $(.072)$ & .007 & $(.126)$ & .026 & $(.116)$ \\
\hline College $^{a}$ & .037 & $(.153)$ & -.044 & $(.094)$ & .055 & $(.065)$ & .092 & $(.117)$ & .097 & $(.106)$ \\
\hline Post graduate degree ${ }^{a}$ & -.008 & $(.159)$ & -.037 & $(.101)$ & .009 & $(.070)$ & .111 & $(.124)$ & .123 & $(.114)$ \\
\hline Personal income ${ }^{b}$ & $-.014 *$ & $(.007)$ & -.002 & $(.005)$ & -.001 & $(.003)$ & -.009 & $(.005)$ & -.007 & $(.005)$ \\
\hline Work hours & -.004 & $(.002)$ & -.001 & $(.002)$ & .001 & $(.001)$ & .002 & $(.002)$ & -.001 & $(.002)$ \\
\hline Spouse's work hours & $-.005^{*}$ & $(.002)$ & -.002 & $(.002)$ & -.001 & $(.001)$ & .001 & $(.002)$ & .001 & $(.002)$ \\
\hline Previous mental health & $.274 * * *$ & $*(.079)$ & $.128 *$ & $(.052)$ & $.107 * *$ & $(.036)$ & .049 & $(.057)$ & -.009 & $(.054)$ \\
\hline Spouse's general health & $-.156 * * *$ & $*(.030)$ & $-.090 * *$ & $*(.019)$ & $-.089 * * *$ & $*(.013)$ & $-.084 * *$ & ${ }^{*}(.021)$ & $-.042 *$ & $(.021)$ \\
\hline Children under 6 & .010 & $(.046)$ & .001 & $(.033)$ & .020 & $(.023)$ & .001 & $(.032)$ & -.001 & $(.033)$ \\
\hline Children 6 to 11 & -.007 & $(.039)$ & $.093 * *$ & $*(.026)$ & .013 & $(.018)$ & -.031 & $(.026)$ & -.047 & $(.031)$ \\
\hline Children 12 to 18 & .008 & $(.043)$ & $.156^{* *}$ & $*(.028)$ & .003 & $(.019)$ & -.028 & $(.029)$ & -.054 & $(.025)$ \\
\hline Domestic tasks & .065 & $(.056)$ & .007 & $(.035)$ & $.157 * * *$ & $*(.024)$ & .025 & $(.041)$ & .006 & $(.040)$ \\
\hline Constant & \multirow{2}{*}{\multicolumn{2}{|c|}{$\begin{array}{c}3.346 * * *(.349) \\
115\end{array}$}} & \multirow{2}{*}{\multicolumn{2}{|c|}{$1.805 * * *(.234)$}} & \multicolumn{2}{|c|}{$.852 * * *(.161)$} & \multicolumn{2}{|c|}{$1.529 * * *(.246)$} & \multirow{2}{*}{\multicolumn{2}{|c|}{$\begin{array}{c}.720 *(.248) \\
.270\end{array}$}} \\
\hline$R^{2}$ & & & & & & 124 & & 09 & & \\
\hline
\end{tabular}

$* p<.05, * * p<.01, * * * p<.001$ two-tailed test.

Notes: SPWFC = Respondent's perceptions of their spouse's work-to-family conflict. RWFC Respondent's work-to-family conflict. ${ }^{a}$ Compared to respondents with less than high school. ${ }^{b}$ Personal income was divided by 10,000 in all analyses. ${ }^{c}$ Indicates a significant mediated effect based on Sobel tests. 
Table 3 Regressions of Psychological Distress on SPWFC, Mediation by Family Stressors and RFWC $(N=1,348)$

\begin{tabular}{|c|c|c|c|c|c|c|c|c|}
\hline \multirow{3}{*}{ Variable } & \multicolumn{8}{|c|}{ Psychological Distress } \\
\hline & \multicolumn{2}{|c|}{ Model 1} & \multicolumn{2}{|c|}{ Model 2} & \multicolumn{2}{|c|}{ Model 3} & \multicolumn{2}{|c|}{ Model 4} \\
\hline & $b$ & SE & $b$ & SE & $b$ & SE & $b$ & SE \\
\hline SPWFC & $.098 * *$ & $*(.018)$ & $.062 * *$ & $*(.018)$ & $.041^{*}$ & $(.017)$ & .027 & $(.017)$ \\
\hline RWFC & - & & $.238 * *$ & $*(.022)$ & $.215^{* *}$ & $*(.022)$ & $.192 *$ & $*(.024)$ \\
\hline \multicolumn{9}{|l|}{ Family Stressors } \\
\hline Spousal disputes & - & & - & & $.097 * *$ & $*(.019)^{c}$ & $.083 *$ & $*(.019)$ \\
\hline Children's problems & - & & - & & $.078 * *$ & $*(.029)^{c}$ & $.054 *$ & $(.029)$ \\
\hline Marital dissatisfaction & - & & - & & $.071 *$ & $(.039)$ & .060 & $(.038)$ \\
\hline RFWC & - & & - & & - & & $.116^{*}$ & $*(.028)^{c}$ \\
\hline \multicolumn{9}{|l|}{ Focal Controls } \\
\hline Gender (female) & $.134 * *$ & $(.051)$ & $.105^{* *}$ & $(.049)$ & $.117 *$ & $(.048)$ & $.112 *$ & $(.047)$ \\
\hline Age & -.007 & $(.003)$ & $-.007 *$ & $(.003)$ & $-.006 *$ & $(.003)$ & $-.006^{*}$ & $(.003)$ \\
\hline White & -.063 & $(.053)$ & -.041 & $(.052)$ & -.023 & $(.051)$ & -.020 & $(.051)$ \\
\hline High school ${ }^{a}$ & -.067 & $(.115)$ & -.046 & $(.111)$ & -.054 & (.109) & -.050 & $(.106)$ \\
\hline Associates degree ${ }^{a}$ & -.082 & $(.117)$ & -.078 & $(.112)$ & -.082 & $(.109)$ & -.087 & $(.106)$ \\
\hline Some college ${ }^{a}$ & -.148 & $(.113)$ & -.113 & $(.110)$ & -.103 & $(.107)$ & -.105 & $(.104)$ \\
\hline College $^{a}$ & -.062 & $(.109)$ & -.073 & $(.107)$ & -.074 & $(.104)$ & -.085 & $(.100)$ \\
\hline Post graduate degree ${ }^{a}$ & -.030 & $(.116)$ & -.049 & $(.113)$ & -.043 & $(.110)$ & -.056 & $(.106)$ \\
\hline Personal income ${ }^{b}$ & .001 & $(.005)$ & .001 & $(.005)$ & .001 & $(.005)$ & .002 & $(.004)$ \\
\hline Work hours & $.005^{* *}$ & $*(.002)$ & -.001 & $(.002)$ & .001 & $(.002)$ & .001 & $(.002)$ \\
\hline Spouse's work hours & -.003 & $(.002)$ & -.001 & $(.002)$ & .001 & $(.002)$ & .001 & $(.002)$ \\
\hline Previous mental health & \multicolumn{2}{|c|}{$.530 * * *(.055)$} & \multicolumn{2}{|c|}{$.393 * * *(.050)$} & \multicolumn{2}{|c|}{$.351 * * *(.049)$} & \multicolumn{2}{|c|}{$.350 * * *(.049)$} \\
\hline Spouse's general health & \multicolumn{2}{|c|}{$-.121 * * *(.019)$} & \multicolumn{2}{|c|}{$-.105 * * *(.018)$} & \multicolumn{2}{|c|}{$-.077 * * *(.018)$} & \multicolumn{2}{|c|}{$-.073 * * *(.018)$} \\
\hline Children under 6 & .011 & $(.031)$ & -.012 & $(.029)$ & -.015 & $(.028)$ & -.020 & $(.028)$ \\
\hline Children 6 to 11 & -.010 & $(.024)$ & -.025 & $(.023)$ & -.032 & $(.023)$ & -.027 & $(.023)$ \\
\hline Children 12 to 18 & .017 & $(.028)$ & .006 & $(.027)$ & -.006 & $(.026)$ & -.002 & $(.026)$ \\
\hline Domestic tasks & -.005 & $(.036)$ & -.010 & $(.034)$ & -.025 & $(.033)$ & -.025 & $(.033)$ \\
\hline Constant & \multicolumn{2}{|c|}{$2.509 * * *(.232)$} & \multicolumn{2}{|c|}{$2.162 * * *(.225)$} & \multicolumn{2}{|c|}{$1.634 * * *(.228)$} & \multicolumn{2}{|c|}{$1.564 * * *(.226)$} \\
\hline$R^{2}$ & \multicolumn{2}{|c|}{.168} & \multicolumn{2}{|c|}{.275} & \multicolumn{2}{|c|}{.308} & \multicolumn{2}{|c|}{.321} \\
\hline
\end{tabular}

$* p<.05, * * p<.01, * * * p<.001$ two-tailed test.

Notes: $\mathrm{SPWFC}=$ Respondent's perceptions of their spouse's work-to-family conflict. RWFC=

Respondent's work-to-family conflict. RFWC=Respondent's family-to-work conflict.

${ }^{a}$ Compared to respondents with less than high school. ${ }^{b}$ Personal income is presented in $\$ 10,000$.

${ }^{c}$ Indicates a significant mediated effect based on Sobel tests. 
Table 4 Regressions of Anger on SPWFC, Mediation by Family Stressors, and RFWC $(N=1,348)$

\begin{tabular}{|c|c|c|c|c|c|c|c|c|}
\hline \multirow{3}{*}{ Variable } & \multicolumn{8}{|c|}{ Anger } \\
\hline & \multicolumn{2}{|c|}{ Model 1} & \multicolumn{2}{|c|}{ Model 2} & \multicolumn{2}{|c|}{ Model 3} & \multicolumn{2}{|c|}{ Model 4} \\
\hline & $b$ & SE & $b$ & SE & $b$ & SE & $b$ & SE \\
\hline SPWFC & $.104 * *$ & $*(.019)$ & $.079 *$ & $*(.019)$ & $.050 *$ & $(.018)$ & $.043^{*}$ & $(.019)$ \\
\hline RWFC & - & & $.166^{*}=$ & $*(.022)$ & $.138 *$ & $*(.022)$ & $.127 * * *$ & *(.023) \\
\hline \multicolumn{9}{|l|}{ Family Stressors } \\
\hline Spousal disputes & - & & - & & $.147 *$ & $*(.020)^{c}$ & $.137 * * *$ & $\mathrm{k}(.020)$ \\
\hline Children's problems & - & & - & & $.098^{*}$ & $*(.027)^{c}$ & $.082 * *$ & $(.027)$ \\
\hline Marital dissatisfaction & - & & - & & .032 & $(.042)$ & .027 & $(.042)$ \\
\hline RFWC & - & & - & & & - & $.065 * *$ & $(.028)^{c}$ \\
\hline \multicolumn{9}{|l|}{ Focal Controls } \\
\hline Gender (female) & .065 & $(.056)$ & .044 & $(.055)$ & .056 & $(.052)$ & .056 & $(.052)$ \\
\hline Age & -.005 & $(.004)$ & -.005 & $(.003)$ & -.003 & $(.003)$ & -.003 & $(.003)$ \\
\hline White & -.004 & $(.053)$ & .012 & $(.052)$ & .037 & $(.051)$ & .039 & $(.051)$ \\
\hline High school ${ }^{a}$ & -.121 & $(.105)$ & -.106 & $(.103)$ & -.114 & $(.099)$ & -.110 & $(.099)$ \\
\hline Associates degree ${ }^{a}$ & -.083 & (.109) & -.080 & $(.107)$ & -.080 & $(.103)$ & -.081 & $(.103)$ \\
\hline Some college ${ }^{a}$ & -.079 & $(.106)$ & -.054 & $(.106)$ & -.039 & $(.102)$ & -.039 & $(.102)$ \\
\hline College $^{a}$ & -.134 & $(.096)$ & -.141 & $(.096)$ & -.140 & $(.092)$ & -.144 & $(.092)$ \\
\hline Post graduate degree ${ }^{a}$ & -.146 & $(.102)$ & -.159 & $(.102)$ & -.151 & $(.099)$ & -.156 & $(.098)$ \\
\hline Personal income ${ }^{b}$ & -.001 & $(.005)$ & -.002 & $(.005)$ & .001 & $(.005)$ & .001 & $(.005)$ \\
\hline Work hours & $.006 * *$ & $*(.002)$ & .002 & $(.002)$ & .003 & $(.002)$ & .003 & $(.002)$ \\
\hline Spouse's work hours & -.002 & $(.002)$ & -.001 & $(.002)$ & .001 & $(.002)$ & .001 & $(.002)$ \\
\hline Previous mental health & $.303 * *$ & $*(.052)$ & $.207 *$ & $*(.051)$ & $.153 *$ & $*(.051)$ & $.148 * * *$ & $*(.050)$ \\
\hline Spouse's general health & $-.086 * *$ & $*(.021)$ & $-.075^{*}$ & $*(.020)$ & $-.041 *$ & $*(.020)$ & $-.040 *$ & $(.020)$ \\
\hline Children under 6 & $.060 *$ & $(.034)$ & .044 & $(.034)$ & .041 & $(.032)$ & .034 & $(.032)$ \\
\hline Children 6 to 11 & .049 & $(.026)$ & .039 & $(.026)$ & .030 & $(.025)$ & .031 & $(.024)$ \\
\hline Children 12 to 18 & .011 & $(.028)$ & .003 & $(.029)$ & -.013 & $(.027)$ & -.014 & $(.027)$ \\
\hline Domestic tasks & .036 & $(.039)$ & .032 & $(.037)$ & .020 & $(.035)$ & .019 & $(.035)$ \\
\hline Constant & $2.391 * *$ & $*(.254)$ & $2.149 *$ & $*(.241)$ & $1.455^{*}$ & $*(.246)$ & $1.425 * * *$ & $*(.244)$ \\
\hline$R^{2}$ & & 01 & & 51 & & 208 & & 210 \\
\hline
\end{tabular}

$* p<.05, * * p<.01, * * * p<.001$ two-tailed test.

Notes: SPWFC = Respondent's perceptions of their spouse's work-to-family conflict. RWFC=

Respondent's work-to-family conflict. RFWC=Respondent's family-to-work conflict.

${ }^{a}$ Compared to respondents with less than high school. ${ }^{b}$ Personal income is presented in $\$ 10,000$.

${ }^{c}$ Indicates a significant mediating effect based on Sobel tests. 
FIGURE 1. Conceptual Framework of Spouse's Work-to-Family Conflict, Family Stressors, Family-to-Work Conflict and Mental Health among Dual Earner Mothers and Fathers

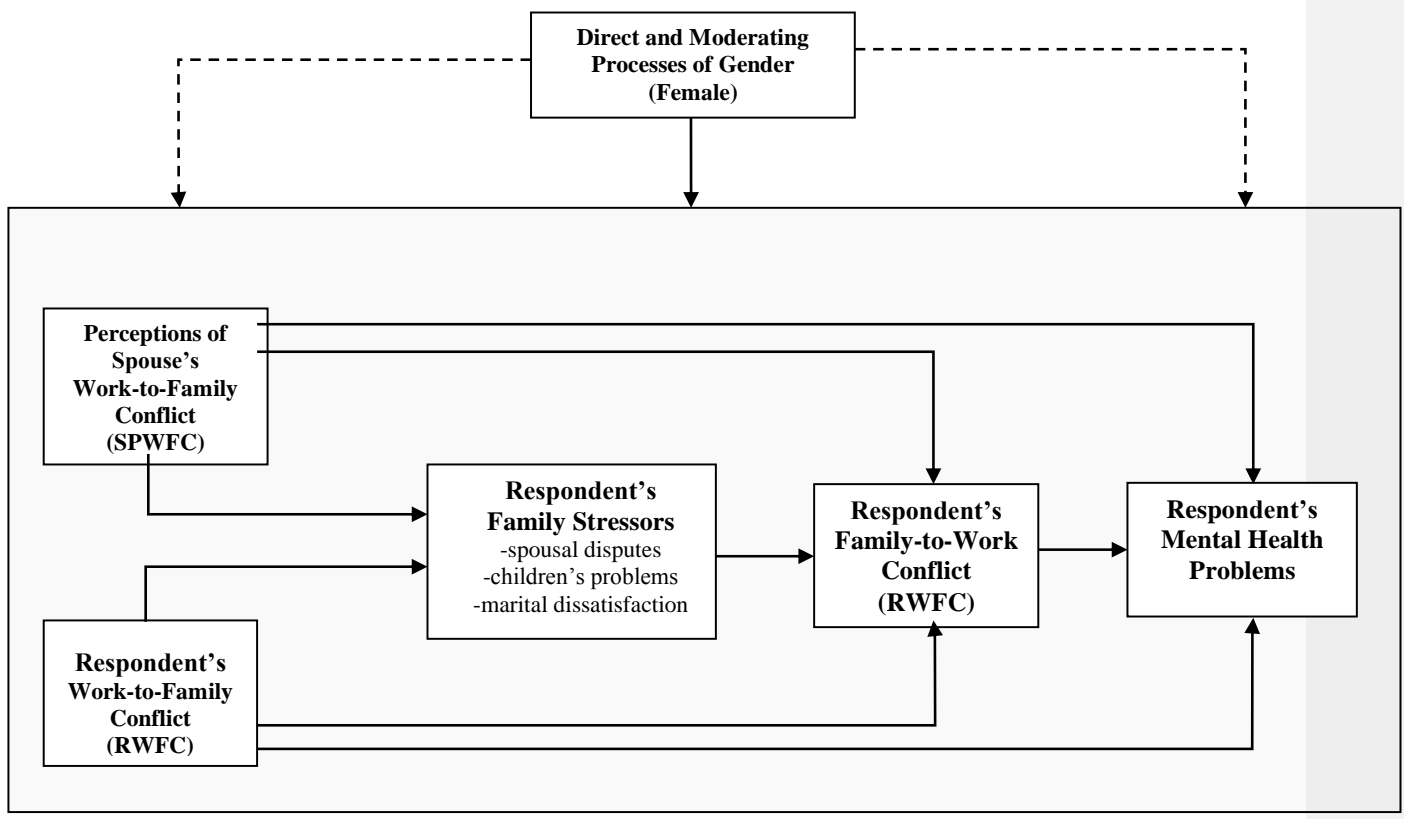

Note: The solid lines represent the direct effects between variables. The dashed lines indicate moderating effects of gender on the association between SPWFC, family stressors, and mental health outcomes. We hypothesize that all associations are positive in direction. 
APPENDIX A. Regression of SPWFC on Spouse's Work-Related Measures $(N=1,348)$

\begin{tabular}{|c|c|c|}
\hline \multirow[b]{2}{*}{ Variable } & \multicolumn{2}{|c|}{ SPWFC } \\
\hline & $b$ & SE \\
\hline Spouse's work hours & \multicolumn{2}{|c|}{$.027 * * *(.003)$} \\
\hline \multicolumn{3}{|l|}{ Spouse's Occupation } \\
\hline Executive $^{a}$ & .108 & $(.090)$ \\
\hline Technical $^{a}$ & $-.181^{*}$ & $(.091)$ \\
\hline Sales ${ }^{a}$ & -.174 & $(.168)$ \\
\hline Administrative $^{a}$ & $-.593 * *$ & $(.118)$ \\
\hline Service $^{a}$ & -.106 & $(.100)$ \\
\hline Production $^{a}$ & $-.186^{*}$ & $(.081)$ \\
\hline Constant & \multicolumn{2}{|c|}{$1.249 * * *$} \\
\hline$R^{2}$ & \multicolumn{2}{|l|}{.118} \\
\hline
\end{tabular}

APPENDIX B. Breakdown of Missing Cases for Family Stressors by Age of Children $(N=1,348$; including missing cases across focal measures)

\begin{tabular}{|c|c|c|c|}
\hline & \multicolumn{3}{|c|}{$\begin{array}{c}\text { Number of Valid Responses by } \\
\text { Age of Child }\end{array}$} \\
\hline & \multicolumn{3}{|c|}{ At least one child... } \\
\hline & $0-5$ & $6-11$ & $12-18$ \\
\hline Family Stressors & Years & Years & Years \\
\hline Spousal disputes (1 item) & 564 & 615 & 632 \\
\hline \multicolumn{4}{|c|}{ Children's problems (3 items) } \\
\hline Problems at school & 499 & 613 & 629 \\
\hline Problems with friends & 562 & 614 & 628 \\
\hline Health related problems & 632 & 615 & 564 \\
\hline \multicolumn{4}{|c|}{ Marital dissatisfaction (3 items) } \\
\hline Feel close to partner & 564 & 615 & 632 \\
\hline Talk about problems & 564 & 615 & 632 \\
\hline Will always be there & 564 & 615 & 632 \\
\hline
\end{tabular}


APPENDIX C. Correlations for Selected Variables $(N=1,348)$

\begin{tabular}{|c|c|c|c|c|c|c|c|c|c|c|c|c|c|c|}
\hline & & 1 & 2 & 3 & 4 & 5 & 6 & 7 & 8 & 9 & 10 & 11 & 12 & \\
\hline 1 & Distress & - & & & & & & & & & & & & \\
\hline 2 & Anger & .57 & 一 & & & & & & & & & & & \\
\hline 3 & SPWFC & .18 & .19 & 一 & & & & & & & & & & \\
\hline 4 & RWFC & .42 & .30 & .15 & - & & & & & & & & & \\
\hline 5 & Spousal disputes & .29 & .31 & .17 & .15 & - & & & & & & & & \\
\hline 6 & Children's problems & .21 & .20 & .14 & .16 & .17 & - & & & & & & & \\
\hline 7 & Marital dissatisfaction & .24 & .21 & .14 & .17 & .39 & .15 & - & & & & & & \\
\hline 8 & RFWC & .36 & .27 & .30 & .35 & .29 & .27 & .23 & - & & & & & \\
\hline 9 & Gender (female) & .12 & .07 & .16 & -.02 & .06 & -.01 & .07 & .08 & & & & & \\
\hline 10 & Age & -.07 & -.09 & -.04 & .01 & -.12 & .07 & .02 & -.07 & -.13 & & & & \\
\hline 11 & White & -.03 & .01 & .04 & -.02 & -.06 & .01 & -.02 & -.04 & .01 & .04 & & & \\
\hline 12 & Less than high school & .02 & .03 & -.08 & .02 & -.01 & .02 & -.02 & -.04 & -.08 & .08 & -.01 & & \\
\hline \multirow[t]{2}{*}{13} & High school & -.02 & -.01 & -.05 & -.06 & -.01 & .01 & .01 & -.10 & -.02 & .01 & .04 & -.09 & \\
\hline & & 1 & 2 & 3 & 4 & 5 & 6 & 7 & 8 & 9 & 10 & 11 & 12 & \\
\hline 14 & Associate degree & .02 & .02 & -.03 & -.01 & .02 & .02 & .03 & .01 & .01 & -.07 & .03 & -.07 & \\
\hline 15 & Some college & -.04 & .02 & .03 & -.06 & -.02 & .03 & -.01 & -.01 & -.03 & .01 & .01 & -.08 & \\
\hline 16 & College & .01 & -.01 & .03 & .04 & .03 & -.03 & .02 & .05 & .08 & -.05 & -.02 & -.18 & \\
\hline 17 & Post graduate degree & .01 & -.03 & .04 & .05 & -.03 & -.01 & -.03 & .04 & -.03 & .08 & -.04 & -.09 & \\
\hline 18 & Personal income ${ }^{a}$ & -.03 & -.05 & -.05 & .08 & -.10 & -.01 & -.04 & -.05 & -.20 & .19 & .02 & -.10 & \\
\hline 19 & Work hours & .03 & .05 & -.10 & .27 & -.06 & .01 & -.03 & -.01 & -.35 & .05 & .04 & .02 & \\
\hline 20 & Spouse's work hours & .05 & .06 & .31 & -.03 & .01 & -.01 & .06 & .09 & .39 & -.09 & .02 & -.06 & \\
\hline 21 & Previous mental health & .30 & .19 & .05 & .19 & .14 & .10 & .13 & .12 & .14 & -.05 & .06 & .01 & \\
\hline 22 & Spouse's health & .03 & -.15 & -.14 & -.10 & -.19 & -.16 & -.22 & -.08 & .01 & -.06 & .09 & -.05 & \\
\hline 23 & Children under 6 & .05 & .06 & .01 & .01 & .07 & -.11 & -.01 & .06 & .03 & -.55 & -.06 & -.04 & \\
\hline 24 & Children 6 to 11 & .02 & .06 & .07 & .02 & .04 & .07 & .04 & .02 & .02 & -.09 & -.02 & .01 & \\
\hline 25 & Children 12 to 18 & .01 & -.04 & -.01 & .03 & -.06 & .16 & .02 & -.04 & -.01 & .49 & .03 & .05 & \\
\hline \multirow[t]{2}{*}{26} & Domestic tasks & -.01 & .10 & .23 & -.01 & .09 & .02 & .19 & .11 & .60 & -.13 & .04 & -.07 & \\
\hline & & 13 & 14 & 15 & 16 & 17 & 18 & 19 & 20 & 21 & 22 & 23 & 24 & 25 \\
\hline 14 & Associate degree & -.14 & & & & & & & & & & & & \\
\hline 15 & Some college & -.15 & -.13 & & & & & & & & & & & \\
\hline 16 & College & -.35 & -.30 & -.31 & & & & & & & & & & \\
\hline 17 & Post graduate degree & -.18 & -.16 & -.16 & -.38 & & & & & & & & & \\
\hline 18 & Personal income ${ }^{a}$ & -.08 & -.11 & -.05 & .03 & .22 & & & & & & & & \\
\hline 19 & Work hours & .03 & -.03 & -.03 & -.03 & .05 & .24 & & & & & & & \\
\hline 20 & Spouse's work hours & -.02 & .01 & .05 & .04 & -.05 & -.13 & -.11 & & & & & & \\
\hline 21 & Previous mental health & -.02 & .06 & .01 & .01 & -.05 & -.05 & -.07 & .07 & & & & & \\
\hline 22 & Spouse's health & .02 & -.07 & .01 & .05 & .01 & .06 & .02 & -.02 & -.07 & & & & \\
\hline 23 & Kids under 6 & -.06 & -.01 & -.02 & .06 & .03 & -.10 & -.05 & .03 & -.01 & .05 & & & \\
\hline 24 & Kids 6 to 11 & -.05 & .06 & -.03 & .04 & -.04 & -.07 & -.10 & .01 & .02 & -.01 & -.16 & & \\
\hline 25 & Kids 12 to 18 & .09 & -.01 & .01 & -.08 & -.01 & .08 & .09 & -.01 & -.01 & -.04 & -.49 & -.26 & \\
\hline 26 & Domestic tasks & -.02 & -.01 & .03 & .04 & -.02 & -.19 & -.34 & .44 & .13 & -.06 & .04 & .04 & -.01 \\
\hline
\end{tabular}

Note: All coefficients greater than .05 are statistically significant at the $\mathrm{p}<.05$ level (two-tailed test). 